Article

\title{
The Influence of Silica Nanoparticles on Ionic Liquid Behavior: A Clear Difference between Adsorption and Confinement
}

\author{
Yaxing Wang ${ }^{1,2}$, Cheng $\mathrm{Li}^{1}$, Xiaojing Guo ${ }^{1}$ and Guozhong $\mathrm{Wu}{ }^{1{ }^{1} *}$
}

1 Shanghai Institute of Applied Physics, Chinese Academy of Sciences, Shanghai 201800, China; E-Mails: wangyaxing@sinap.ac.cn (Y.W.); licheng@sinap.ac.cn (C.L.); guoxiaojing@sinap.ac.cn (X.G.)

2 Graduate University of Chinese Academy of Sciences, Beijing 100049, China

* Author to whom correspondence should be addressed; E-Mail: wuguozhong@sinap.ac.cn; Tel./Fax: +86-21-3919-4531.

Received: 12 August 2013; in revised form: 26 September 2013 / Accepted: 29 September 2013 / Published: 18 October 2013

\begin{abstract}
The phase behaviors of ionic liquids (ILs) confined in nanospace and adsorbed on outer surface of nanoparticles are expected to be different from those of the bulk. Anomalous phase behaviors of room temperature ionic liquid tributylhexadecylphosphonium bromide $\left(\mathrm{P}_{44416} \mathrm{Br}\right)$ confined in ordered mesoporous silica nanoparticles with average pore size $3.7 \mathrm{~nm}$ and adsorbed on outer surface of the same silica nanoparticles were reported. It was revealed that the melting points $\left(T_{\mathrm{m}}\right)$ of confined and adsorbed ILs depressed significantly in comparison with the bulk one. The $T_{\mathrm{m}}$ depressions for confined and adsorbed ILs are $8{ }^{\circ} \mathrm{C}$ and $14{ }^{\circ} \mathrm{C}$, respectively. For comparison with the phase behavior of confined $\mathrm{P}_{44416} \mathrm{Br}$, 1-butyl-3-methylimidazolium bromide (BmimBr) was entrapped within silica nanopores, we observed an enhancement of $50{ }^{\circ} \mathrm{C}$ in $T_{\mathrm{m}}$ under otherwise similar conditions. The XRD analysis indicates the formation of crystalline-like phase under confinement, in contrast to the amorphous phase in adsorbed IL. It was confirmed that the behavior of IL has clear difference. Moreover, the complex $\pi$ - $\pi$ stacking and H-bonding do not exist in the newly proposed phosphonium-based IL in comparison with the widely studied imidazolium-based IL. The opposite change in melting point of $\mathrm{P}_{44416} \mathrm{Br} @ \mathrm{SiO}_{2}$ and $\mathrm{BmimBr} @ \mathrm{SiO}_{2}$ indicates that the cationic species plays an important role in the variation of melting point.
\end{abstract}

Keywords: confinement; adsorption; ionic liquid; melting point; phase behavior 


\section{Introduction}

Room temperature ionic liquids (ILs), solely composed of organic cations and inorganic/organic anions of varying sizes, have received considerable attention in past years due to a wide range of applications and scientific research interests [1-3]. The tunable cations and anions lead to their peculiar chemical and physical properties, for example, negligible volatility, thermal stability, nonflammability, and high ionic conductivity and so forth. In recent years, many researchers focused on developing ILs for certain application and synthesizing a series of promising hybrid ionogel material [4-7], in which the ILs exist under the confinement or immobilization environment. As a matter of fact, several reports including theoretical and experimental work have found the anomalous phase behavior of ILs and other liquid confined in nanospace or immobilized on the surface of nanoparticles. The obvious difference between confined or adsorbed ILs and the bulk is the dramatic change in melting point ( $\left.T_{\mathrm{m}}\right)$. Kanakubo et al. [8] found that $T_{\mathrm{m}}$ was depressed as $30{ }^{\circ} \mathrm{C}$ in comparison with the bulk when $(\mathrm{Bmim})\left(\mathrm{CF}_{3} \mathrm{SO}_{3}\right)$ and $(\mathrm{Bmim})\left(\left(\mathrm{CF}_{3} \mathrm{SO}_{3}\right)_{2} \mathrm{~N}\right)$ were confined within CPGs (controlled-pore glasses). Kim et al. [9] reported the melting point enhancement of imidazolium-based ILs confined in GMLs (graphene multilayers). Recently, our group found [10] that the interfacial effects and hydrogen-bonding networks between ILs and nano-SiO $\mathrm{x}_{\mathrm{x}}$ are responsible for the decrease of melting point of ILs. Moreover, we elucidated [11] that compressed gas within nanopores plays an important role in changing the melting point of confined ILs. The previous works have shown that nanoconfinement procedures as well as different nanoporous materials all contribute to the change in phase behavior of ILs. Furthermore, mesoporous materials with well-defined pore structures which could be easily synthesized and modified have great potential for separation, catalysis, semiconductive materials and so on [12]. Design for confined nanospaces incorporating with special guest molecules and atoms in metallocages and metal-organic frameworks also move on the development of functional materials $[13,14]$.

With the combination of our continuous efforts to investigate the phase behavior of imidazolium-based ILs on the surface of mica [15], polystyrene submicrospheres [16], inside of multiwalled carbon nanotubes [17] and $\mathrm{SiO}_{2}$ nanopores [18], in this study, new proposed phosphonium-based IL $\mathrm{P}_{44416} \mathrm{Br}$ was filled into $\mathrm{SiO}_{2}$ nanopore under conditions of ultrahigh vacuum and adsorbed onto the outer surface of $\mathrm{SiO}_{2}$ by stirring the IL and $\mathrm{SiO}_{2}$ in a vessel, respectively. The difference between the newly proposed IL $\mathrm{P}_{44416} \mathrm{Br}$ and the widely used imidazolium-based IL is the distinct cationic species: the former consists of an atom phosphorus center and a hydrocarbon skeleton. Thus, the complex $\pi$ - $\pi$ stacking and $\mathrm{H}$-bonding do not exist in $\mathrm{P}_{44416} \mathrm{Br}$. For comparison, we also entrapped imidazolium-based IL $\mathrm{BmimBr}$ within the same type of $\mathrm{SiO}_{2}$ nanopores. Differential scanning calorimetry (DSC) was employed to detect the phase behaviors of confined and adsorbed ILs. We observed a significant $T_{\mathrm{m}}$ depression for both confined and adsorbed $\mathrm{P}_{44416} \mathrm{Br}$, but the depression is more pronounced for the adsorbed one; however, the contrast experiment indicated the enhancement $T_{\mathrm{m}}$ of $\mathrm{BmimBr}$ confined in $\mathrm{SiO}_{2}$ nanopore. X-ray diffraction analysis was performed to investigate the property variation of ILs existing in two independent circumstances. 


\section{Results and Discussion}

The ionic liquids in this study have different cations and their models are shown in Figure 1. The new proposed phosphonium-based IL tributylhexadecylphosphonium bromide $\left(\mathrm{P}_{44416} \mathrm{Br}\right)$ is entrapped within ordered mesoporous $\mathrm{SiO}_{2}$ with pore size $3.7 \mathrm{~nm}$ at $100{ }^{\circ} \mathrm{C}$ under conditions of ultrahigh vacumm $\left(1 \times 10^{-5} \mathrm{~Pa}\right)$. By this procedure, as illustrated in our previous work [11], the air in the cavities of $\mathrm{SiO}_{2}$ particles could be completely removed and the IL could be easily entrapped in cavities of $\mathrm{SiO}_{2}$. The IL-filled samples will hereafter be referred to as $\mathrm{P}_{44416} \mathrm{Br} @ \mathrm{SiO}_{2}$. The TGA analysis shows that the loading amount of IL in $\mathrm{P}_{44416} \mathrm{Br} @ \mathrm{SiO}_{2}$ is 39 wt\%. Surface adsorption experiment for $\mathrm{P}_{44416} \mathrm{Br}$ and $\mathrm{SiO}_{2}$ in a mass ratio of 39:100 was also carried out, and the sample was abbreviated to $\mathrm{P}_{44416} \mathrm{Br} / \mathrm{SiO}_{2}$. Transmission electron microscopy (TEM) was conducted to characterize the morphology of $\mathrm{SiO}_{2}, \mathrm{P}_{44416} \mathrm{Br} / \mathrm{SiO}_{2}$ and $\mathrm{P}_{44416} \mathrm{Br} @ \mathrm{SiO}_{2}$. As shown in Figure 2, the confined IL in the $\mathrm{P}_{44416} \mathrm{Br} @ \mathrm{SiO}_{2}$ reveals clearly that some IL is entrapped in the channel of $\mathrm{SiO}_{2}$ (as indicated by arrows in Figure 2c), while the surface adsorption experiment shows that the $\mathrm{SiO}_{2}$ is covered with IL (as shown in Figure 2b). The morphology of confined IL is consistent with the work by Ji et al. [19], who reported the tungsten carbide confined in the channels of SBA-15 mesoporous silica.

Figure 1. Two types of ionic liquids with various cations and the same anion.

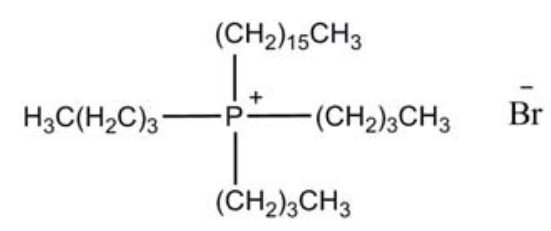

Tributylhexadecylphosphonium bromide

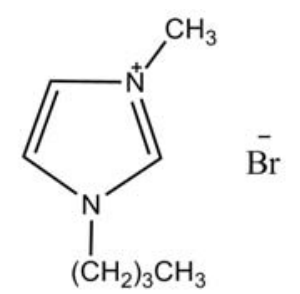

1-Butyl-3-methylimidazolium bromide

Figure 2. TEM images and the corresponding EDX spectra of $\mathrm{SiO}_{2}$ nanoparticles (a,d), $\mathrm{P}_{44416} \mathrm{Br} / \mathrm{SiO}_{2}$ (b,e), and $\mathrm{P}_{44416} \mathrm{Br} @ \mathrm{SiO}_{2}$ (c,f). The scale bar in (a) applies to all three images. The arrows show the existence of ILs in nanopores.
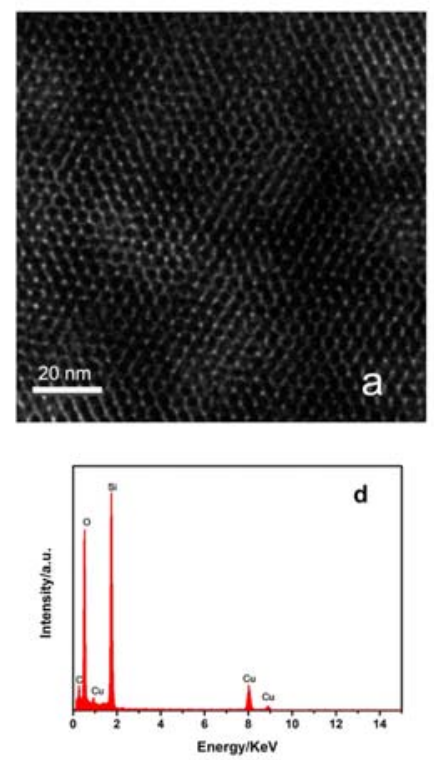
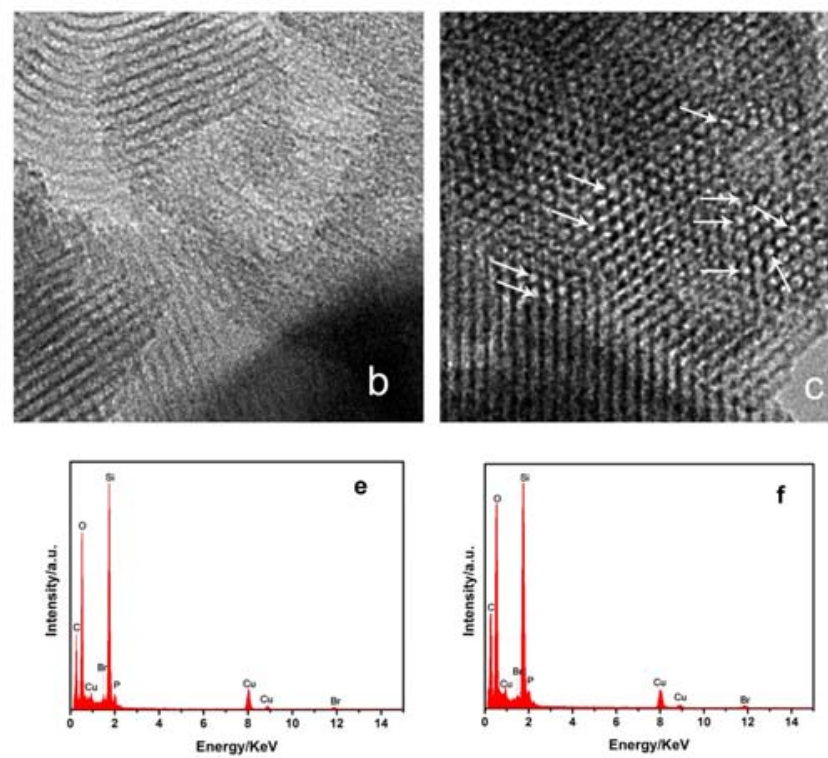
To investigate the phase behavior change of ILs, DSC experiments were carried out. Figure $3 \mathrm{~A}$ shows DSC curves for $\mathrm{P}_{44416} \mathrm{Br} / \mathrm{SiO}_{2}$, bulk $\mathrm{P}_{44416} \mathrm{Br}$, and $\mathrm{P}_{44416} \mathrm{Br} @ \mathrm{SiO}_{2}$. The melting point of $\mathrm{P}_{44416} \mathrm{Br} / \mathrm{SiO}_{2}$ is observed to be $55{ }^{\circ} \mathrm{C}$, being $14{ }^{\circ} \mathrm{C}$ lower than that of the bulk $\mathrm{P}_{44416} \mathrm{Br}$. Our result is in good agreement with the literature [20] in which a remarkable depression $T_{\mathrm{m}}$ is also observed when imidazolium-based IL is immobilized on the surface of $\mathrm{SiO}_{2}$. The reduction of $T_{\mathrm{m}}$ in our results is mainly attributed to the interaction between IL and $\mathrm{SiO}_{2}$. As illustrated in the literature [21], the intermolecular interactions between IL and surface will decrease the mobility of cations near the interface, the cations trend to absorb onto the surface, and thus the cations are trapped in a higher entropic state, leading to a depression in $T_{\mathrm{m}}$ [22]. The H-bonding between IL and hydroxyl of surface will possibly lead to an increase in $T_{\mathrm{m}}$, but the overall effect observed is the depression in $T_{\mathrm{m}}$. However, a novel depression in melting point of confined ILs was observed when $\mathrm{P}_{44416} \mathrm{Br}$ was entrapped in $\mathrm{SiO}_{2}$. The melting point of $\mathrm{P}_{44416} \mathrm{Br} @ \mathrm{SiO}_{2}$ is $61{ }^{\circ} \mathrm{C}$, which is $8{ }^{\circ} \mathrm{C}$ lower than that of pristine $\mathrm{P}_{44416} \mathrm{Br}$ (Figure 3A). As reported in previous works [9,17,18], the nanoconfinement can lead to the enhancement of $T_{\mathrm{m}}$, while, in this case, the depression in $T_{\mathrm{m}}$ of confined ILs $\mathrm{P}_{44416} \mathrm{Br}$ is mostly due to the choice of different cationic species. For comparison, imidazolium-based IL BmimBr was entrapped within $\mathrm{SiO}_{2}$, an elevation of $T_{\mathrm{m}}$ was observed (Figure 3B). In nanoconfinement, IL will be compressed leading to a reduction in distance between anion and cation [18]. We supposed that the reduction in distance between anion and cation will result in the compression of $\mathrm{C}-\mathrm{H} \cdots$ Br hydrogen bonding that exists in imidazolium-based IL, this as well as strengthened coulomb force resulting from compression play important roles leading to an increased melting point of confined ILs. Konstantin [23] also reported an increased melting point originating from the presence of extremely short $\mathrm{C}-\mathrm{H} \cdots \mathrm{F}$ contacts in the crystal and atomistic molecular dynamics simulation illustrated that imidazolium-based IL formed the dramatic hydrogen-bonded network structure under confinement [24,25]. The compression of confined IL ought to be a general phenomenon. In sample $\mathrm{P}_{44416} \mathrm{Br} @ \mathrm{SiO}_{2}$ the compression will strengthen the coulomb force and enhance the melting point of confined IL, the absence of $\mathrm{C}-\mathrm{H} \cdots \mathrm{Br}$ hydrogen bonding and the IL-wall interaction should all contribute to the change in melting point; thus, the integrative effects depressed the melting point. This is the reason that the melting point of $\mathrm{P}_{44416} \mathrm{Br} @ \mathrm{SiO}_{2}$ is higher than that of $\mathrm{P}_{44416} \mathrm{Br} / \mathrm{SiO}_{2}$. In other words, the cationic species, which would result in the different interaction between cation and anion, plays a non-negligible role in changing the melting point of confined ILs.

Figure 3. Differential scanning calorimetry (DSC) heating curves for (A) $\mathrm{P}_{44416} \mathrm{Br} / \mathrm{SiO}_{2}$; $\mathrm{P}_{44416} \mathrm{Br} ; \mathrm{P}_{44416} \mathrm{Br} @ \mathrm{SiO}_{2} ;(\mathbf{B}) \mathrm{BmimBr} ; \mathrm{BmimBr} @ \mathrm{SiO}_{2}$.
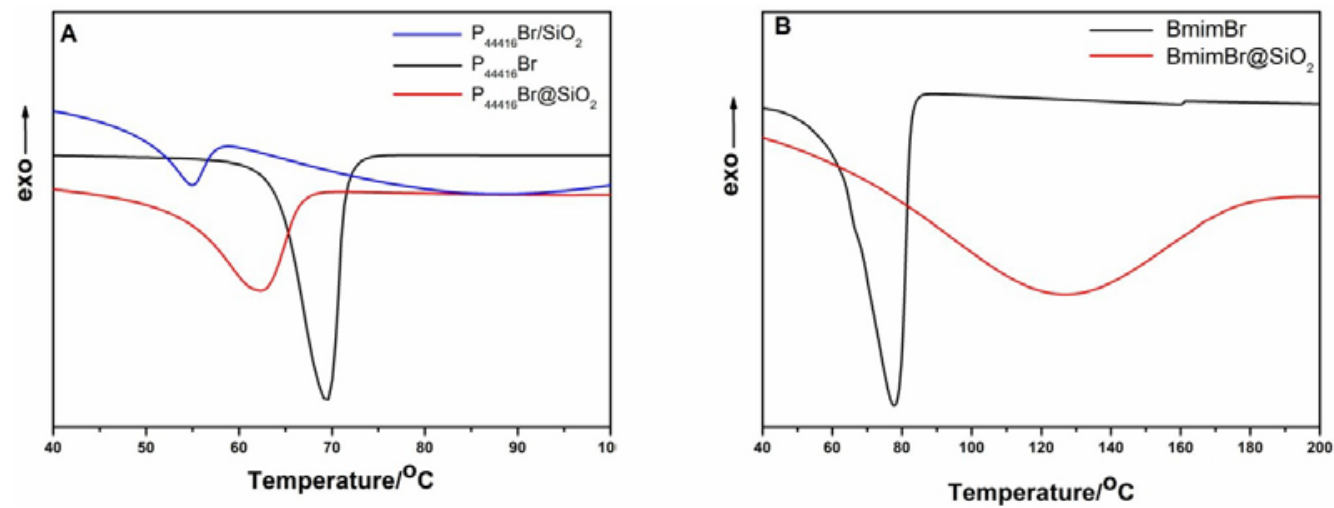
It is generally believed that the confinement effect can lead to the structural vibration of IL. Molecular dynamics simulations reported that 1,3-dimethylimidazolium chloride undergoes a liquid-to-solid transition under the confinement of graphite walls and 1-butyl-3-methylimidazolium hexafluorophosphate possesses long-range crystalline order at $300 \mathrm{~K}$ in carbon nanopore [26,27]. To further understand the structural variation of confined and adsorbed ILs, the X-ray diffraction measurement was employed. Figure 4A implies the formation of crystalline state of the confined ILs, some new peaks appear in comparison with the bulk $\mathrm{P}_{44416} \mathrm{Br}$. However, as illustrated in Figure 4B, the $\mathrm{P}_{44416} \mathrm{Br} / \mathrm{SiO}_{2}$ is speculated to be amorphous, the wide-bound peak between $15^{\circ}$ and $30^{\circ}$ is due to the amorphous peak of $\mathrm{SiO}_{2}$. It is noted that the bulk $\mathrm{P}_{44416} \mathrm{Br}$ has crystal-like structure and the XRD analysis indicates that the conformation or stacking of ILs under confinement or adsorption has critical change. The influence of silica nanoparticles on the behavior of $\mathrm{P}_{44416} \mathrm{Br}$ is further proved from the enthalpy of fusion for bulk $\mathrm{P}_{44416} \mathrm{Br}, \mathrm{P}_{44416} \mathrm{Br} @ \mathrm{SiO}_{2}$ and $\mathrm{P}_{44416} \mathrm{Br} / \mathrm{SiO}_{2}$, shown in Table 1. Different enthalpy of fusions between $\mathrm{P}_{44416} \mathrm{Br} @ \mathrm{SiO}_{2}$ and $\mathrm{P}_{44416} \mathrm{Br} / \mathrm{SiO}_{2}$ indicate the difference in structure for confined and adsorbed ILs. The interfacial effect and hydroxyl of surface most likely disarrange the structure of the adsorbed IL and confinement may result in "compact stacking” (Scheme 1).

Table 1. Enthalpy of fusion for bulk $\mathrm{P}_{44416} \mathrm{Br}, \mathrm{P}_{44416} \mathrm{Br} @ \mathrm{SiO}_{2}$ and $\mathrm{P}_{44416} \mathrm{Br} / \mathrm{SiO}_{2}$.

\begin{tabular}{cccc}
\hline & $\mathbf{P}_{\mathbf{4 4 4 1 6}} \mathbf{B r}$ & $\mathbf{P}_{\mathbf{4 4 4 1 6}} \mathbf{B r} @ S \mathbf{S i O}_{2}$ & $\mathbf{P}_{\mathbf{4 4 4 1 6}} \mathbf{B r} / \mathbf{S i O}_{2}$ \\
\hline Enthalpy of fusion $/ \mathrm{J} \cdot \mathrm{g}^{-1}$ & 73.02 & 21.67 & 17.90 \\
\hline
\end{tabular}

Figure 4. XRD patterns of the bulk $\mathrm{P}_{44416} \mathrm{Br}$ and the sample $\mathrm{P}_{44416} \mathrm{Br} @ \mathrm{SiO}_{2}$. Inset: XRD pattern of sample $\mathrm{P}_{44416} \mathrm{Br} / \mathrm{SiO}_{2}$.

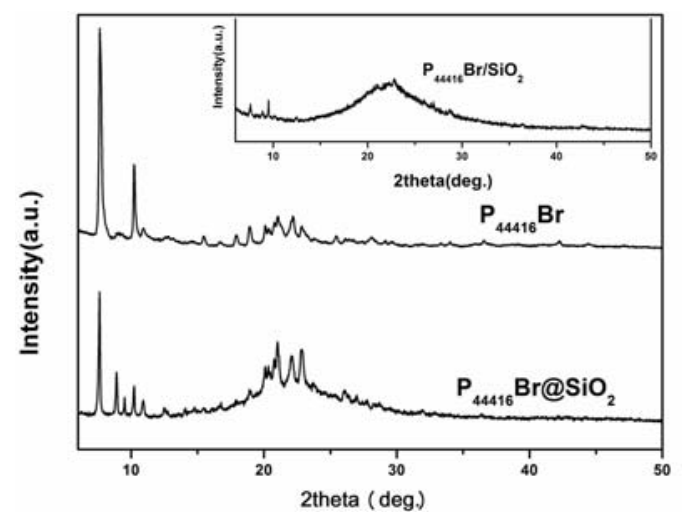

Scheme 1. Schematic diagram of the influence of silica nanoparticles on ionic liquid behavior.

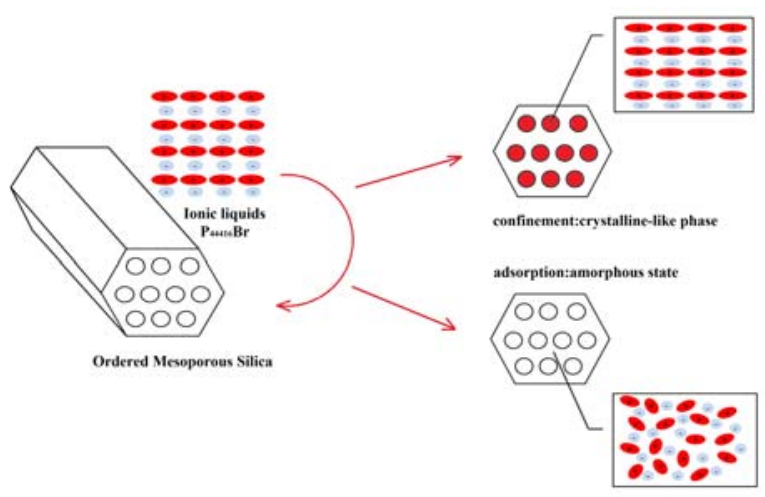




\section{Experimental Section}

\subsection{Materials}

$\mathrm{P}_{44416} \mathrm{Br}$, BmimBr ionic liquids, silica nanoparticles and methanol were obtained from Sigma-Aldrich $^{\circledR}$ (Shanghai, China). The average pore diameter of silica is $3.7 \mathrm{~nm}$. All the materials were reagent grade and used as purchased.

\subsection{Experimental Details}

Exactly $214.6 \mathrm{mg} \mathrm{\textrm {SiO } _ { 2 }}$ was put into a two-necked flask (one of the necks was connect with a high-vacuum line and the others was sealed). The flask was heated $100{ }^{\circ} \mathrm{C}$ for $6 \mathrm{~h}$ under vacuum $\left(1 \times 10^{-5} \mathrm{~Pa}\right)$ to remove the gas and water in the cavities of $\mathrm{SiO}_{2}$ nanopores. Then $436.2 \mathrm{mg} \mathrm{P}_{44416} \mathrm{Br}$ ionic liquids dissolved in methanol was transferred into the flask through a syringe and the mixture was subsequently heated at $100{ }^{\circ} \mathrm{C}$ for $6 \mathrm{~h}$. The $\mathrm{P}_{44416} \mathrm{Br}$ ionic liquid filled into the cavities of $\mathrm{SiO}_{2}$. The as-prepared product was cooled to room temperature and washed with methanol to remove the $\mathrm{P}_{44416} \mathrm{Br}$ adsorbed on the outer surface of $\mathrm{SiO}_{2}$ and then dried at $50{ }^{\circ} \mathrm{C}$ in an oven for $12 \mathrm{~h}$ to remove any volatiles to obtain the final sample $\mathrm{P}_{44416} \mathrm{Br} @ \mathrm{SiO}_{2}$. The same procedure was employed for the preparation of $\mathrm{BmimBr} @ \mathrm{SiO}_{2}$.

Exactly $430.3 \mathrm{mg} \mathrm{SiO}_{2}$ and $168.2 \mathrm{mg} \mathrm{P}_{44416} \mathrm{Br}$ ionic liquid (mass ratio $=100: 39$ ) were added to an appropriate amount of methanol solution in a glass beaker. The solution was stirred for $24 \mathrm{~h}$ and then dried at $50{ }^{\circ} \mathrm{C}$ in an oven for $12 \mathrm{~h}$ to remove any volatiles to obtain the final sample $\mathrm{P}_{44416} \mathrm{Br} / \mathrm{SiO}_{2}$.

\subsection{Characterizations}

Phase behaviors of the bulk $\mathrm{P}_{44416} \mathrm{Br}$, the sample $\mathrm{P}_{44416} \mathrm{Br} @ \mathrm{SiO}_{2}$ and $\mathrm{P}_{44416} \mathrm{Br} / \mathrm{SiO}_{2}$ were determined by differential scanning calorimetry (DSC-822e, Mettler-Toledo Corp.). The programmed heating rate is $10{ }^{\circ} \mathrm{C} / \mathrm{min}$, the sample about $12 \mathrm{mg}$ was placed in an aluminum pans with pierced lids.

X-ray diffraction (XRD) measurement patterns were recorded with a Philips X-ray diffractometer (PW-1710) using $\mathrm{Cu} \mathrm{K}_{\alpha}$ radiation ranging from $5^{\circ}$ to $50^{\circ}$.

Transmission electron microscopy (TEM) was performed on a Zeiss EM 912 operated at $120 \mathrm{kV}$.

\section{Conclusions}

In summary, we studied the phase behavior of phosphonium-based IL $\mathrm{P}_{44416} \mathrm{Br}$ in two independent circumstances (adsorption and confinement). We observed a remarkable depression in $T_{\mathrm{m}}$, the melting point of adsorbed IL, $\mathrm{P}_{44416} \mathrm{Br} / \mathrm{SiO}_{2}$, was lower than that of confined IL, $\mathrm{P}_{44416} \mathrm{Br} @ \mathrm{SiO}_{2}$, and all two samples have a depressed melting point in comparison with the bulk one. The XRD measurement further illustrated different structural variation of $\mathrm{P}_{44416} \mathrm{Br}$ in two independent circumstances. In the context of previous work and the phase behavior of imidazolium-based IL confined in silica, BmimBr@SiO $\mathrm{SiO}_{2}$, our results indicated that the cationic species plays an important role in changing the melting point. It was assumed that the interfacial effect and hydroxyl of surface are responsible for depression in melting point of the adsorbed $\mathrm{P}_{44416} \mathrm{Br}$ and that the confinement effect and interaction of IL contributed to the change in the melting point of confined $\mathrm{P}_{44416} \mathrm{Br}$. 


\section{Acknowledgments}

This work was supported by the National Natural Science Foundation of China No. 11079007.

\section{Conflicts of Interest}

The authors declare no conflict of interest.

\section{References}

1. Welton, T. Room-temperature ionic liquids. Solvents for synthesis and catalysis. Chem. Rev. 1999, 99, 2071-2083.

2. Hallett, J.P.; Welton, T. Room-Temperature Ionic Liquids: Solvents for Synthesis and Catalysis. 2. Chem. Rev. 2011, 111, 3508-3576.

3. Zhang, Q.; Zhang, S.; Deng, Y. Recent advances in ionic liquid catalysis. Green Chem. 2011, 13, 2619-2637.

4. Neouze, M.-A.; Le Bideau, J.; Gaveau, P.; Bellayer, S.; Vioux, A. Ionogels, new materials arising from the confinement of ionic liquids within silica-derived networks. Chem. Mater. 2006, 18, 3931-3936.

5. Neouze, M.A.; Le Bideau, J.; Leroux, F.; Vioux, A. A route to heat resistant solid membranes with performances of liquid electrolytes. Chem. Commun. 2005, 1082-1084.

6. Shi, F.; Zhang, Q.H.; Li, D.M.; Deng, Y.Q. Silica-gel-confined ionic liquids: A new attempt for the development of supported nanoliquid catalysis. Chem. Eur. J. 2005, 11, 5279-5288.

7. Goebel, R.; Friedrich, A.; Taubert, A. Tuning the phase behavior of ionic liquids in organically functionalized silica ionogels. Dalton Trans. 2010, 39, 603-611.

8. Kanakubo, M.; Hiejima, Y.; Minami, K.; Aizawa, T.; Nanjo, H. Melting point depression of ionic liquids confined in nanospaces. Chem. Commun. 2006, 1828-1830.

9. Im, J.; Cho, S.D.; Kim, M.H.; Jung, Y.M.; Kim, H.S.; Park, H.S. Anomalous thermal transition and crystallization of ionic liquids confined in graphene multilayers. Chem. Commun. 2012, 48, 2015-2017.

10. Liu, Y.; Wu, G.; Fu, H.; Jiang, Z.; Chen, S.; Sha, M. Immobilization and melting point depression of imidazolium ionic liquids on the surface of nano-SiOx particles. Dalton Trans. 2010, 39, 3190-3194.

11. Chen, S.; Liu, Y.; Fu, H.; He, Y.; Li, C.; Huang, W.; Jiang, Z.; Wu, G. Unravelling the role of the compressed gas on melting point of liquid confined in nanospace. J. Phys. Chem. Lett. 2012, 3, 1052-1055.

12. Ariga, K.; Vinu, A.; Yamauchi, Y.; Ji, Q.; Hill, J.P. Nanoarchitectonics for mesoporous materials. Bull. Chem. Soc. Jpn. 2012, 85, 1-32.

13. Li, J.-R.; Sculley, J.; Zhou, H.-C. Metal-organic frameworks for separations. Chem. Rev. 2012, 112, 869-932.

14. Amouri, H.; Desmarets, C.; Moussa, J. Confined nanospaces in metallocages: Guest molecules, weakly encapsulated anions, and catalyst sequestration. Chem. Rev. 2012, 112, 2015-2041. 
15. Liu, Y.D.; Zhang, Y.; Wu, G.Z.; Hu, J. Coexistence of liquid and solid phases of Bmim-PF6 ionic liquid on mica surfaces at room temperature. J. Am. Chem. Soc. 2006, 128, 7456-7457.

16. He, Y.; Fu, H.; Li, C.; Ji, X.; Ge, X.; Zou, Y.; Jiang, Z.; Xu, H.; Wu, G. Property variation of ionic liquid Bmim AuCl4 immobilized on carboxylated polystyrene submicrospheres with a small surface area. Chin. Sci. Bull. 2013, 58, 2950-2955.

17. Chen, S.; Wu, G.; Sha, M.; Huang, S. Transition of ionic liquid bmim PF6 from liquid to high-melting-point crystal when confined in multiwalled carbon nanotubes. J. Am. Chem. Soc. 2007, 129, 2416-2417.

18. Li, C.; Guo, X.; He, Y.; Jiang, Z.; Wang, Y.; Chen, S.; Fu, H.; Zou, Y.; Dai, S.; Wu, G.; et al. Compression of ionic liquid when confined in porous silica nanoparticles. RSC Adv. 2013, 3, 9618-9621.

19. Hu, L.; Ji, S.; Xiao, T.; Guo, C.; Wu, P.; Nie, P. Preparation and characterization of tungsten carbide confined in the channels of SBA-15 mesoporous silica. J. Phys. Chem. B 2007, 111, 3599-3608.

20. Liu, Y.-S.; Fu, H.-Y.; Tang, Z.-F.; Huang, W.; Wu, G.-Z. Melting point and structure of ionic liquid EMIM PF6 on the surface of Nano-SiOx particles. Acta Phys. Chim. Sin. 2011, 27, $1725-1729$.

21. Trofymluk, O.; Levchenko, A.A.; Navrotsky, A. Interfacial effects on vitrification of confined glass-forming liquids. J. Chem. Phys. 2005, 123, 194509.

22. Huck, W.T.S. Effects of nanoconfinement on the morphology and reactivity of organic materials. Chem. Commun. 2005, 4143-4148.

23. Golovanov, D.G.; Lyssenko, K.A.; Antipin, M.Y.; Vygodskii, Y.S.; Lozinskaya, E.I.; Shaplov, A.S. Extremely short $\mathrm{C}-\mathrm{H}$ center dot center dot center dot F contacts in the 1-methyl-3-propylimidazolium SiF6-the reason for ionic "liquid" unexpected high melting point. Crystengcomm 2005, 7, 53-56.

24. Sha, M.; Wu, G.; Liu, Y.; Tang, Z.; Fang, H. Drastic phase transition in ionic liquid dmim CI confined between graphite walls: New phase formation. J. Phys. Chem. C 2009, 113, 4618-4622.

25. Dong, K.; Zhou, G.; Liu, X.; Yao, X.; Zhang, S.; Lyubartsev, A. Structural evidence for the ordered crystallites of ionic liquid in confined carbon nanotubes. J. Phys. Chem. C 2009, 113, 10013-10020.

26. Sha, M.; Wu, G.; Fang, H.; Zhu, G.; Liu, Y. Liquid-to-solid phase transition of a 1,3-dimethylimidazolium chloride ionic liquid monolayer confined between graphite walls. J. Phys. Chem. C 2008, 112, 18584-18587.

27. Dou, Q.; Sha, M.; Fu, H.; Wu, G. Melting transition of ionic liquid bmim PF6 crystal confined in nanopores: A molecular dynamics simulation. J. Phys. Chem. C 2011, 115, 18946-18951.

(C) 2013 by the authors; licensee MDPI, Basel, Switzerland. This article is an open access article distributed under the terms and conditions of the Creative Commons Attribution license (http://creativecommons.org/licenses/by/3.0/). 